\title{
Gestión intergubernamental y capacidad estratégica en el desarrollo local y regional fronterizo
}

Resumen: El artículo tiene como objetivo principal examinar el papel de los gobiernos locales en el desarrollo regional de la frontera norte de México, con base en los enfoques de la gestión intergubernamental de políticas públicas y la capacidad estratégica. La aportación teórica de este artículo consiste en destacar y especificar el papel de la gestión en las políticas de desarrollo fronterizo, con base en la capacidad de los recursos humanos, administrativa $y$, en general, gubernamental. Asimismo, se fundamenta la gestión intergubernamental en materia de asuntos fronterizos, en especial en el ámbito local y a su vez, la gestión de problemas transfronterizos. La pregunta central del artículo es: ¿los gobiernos fronterizos cuentan con las capacidades para promover el desarrollo regional en un contexto fronterizo y transfronterizo?

La premisa que se plantea concibe que una mayor y eficaz cooperación entre los tres ámbitos de gobierno (local, estatal y federal), en materia de desa

\footnotetext{
* Profesor-investigador del Departamento de Estudios en Administración Pública, El Colegio de la Frontera Norte Se le puede enviar correspondencia a Blvd. Abelardo L. Rodríguez no. 2925, Zona del Río, C. P. 22320, Tijuana, Baja California. Teléfono: 01(664) 631-35-35 ext 1220.Correo electrónico: ramosjm@ colef.mx
} 
rrollo regional, y sustentada en una capacidad estraté gica, coadyuva a una mejor gestión e implantación de las políticas.

Los temas generales del artículo son: 1.Antecedentes de las teorías de crecimiento y de política regional, donde se destaca la importancia de la gestión y políticas públicas en las principales teorías del crecimiento y de la política regional; 2. Gestión pública, capacidad y gestión intergubernamental;se examinan algunos antecedentes generales de la gestión pública y se define el concepto de capacidad gubernamental y su impacto en el desarrollo regional, así como la importancia de la gestión intergubernamental, y 3. Problemas fronterizos y nuevos enfoques en la gestión del desarrollo regional; se analizan algunos problemas fronterizos, con la finalidad de destacar ciertas limitaciones en la capacidad gubernamental; en ese contexto, se proponen nuevas estrategias de gestión y políticas locales.

Palabras clave: gestión intergubernamental de políticas públicas, capacidad estratégica, desarrollo regional, cooperación eficaz, teorías de crecimiento.

Abstract: On the basis of the approaches to intergovernmental management of policies and to strategic ability, the main objective of this paper is to examine the role played by local governments in the regional development of the Mexican Northern border. The theoretical contribution of this article entails emphasizing and specifying the role played by management in border development policies based on the managerial and, in general, government ability of human resources

Likewise, intergovernmental management with regard to border affairs, specially at the local level, as 
well as transborder problems management, is established. The main inquiry in this paper is: do border governments have the abilities to promote regional development in a border and transborder context?

The premise set forth here is that a greater and effective cooperation between the three government levels - local, state and federal- with regard to regional development and supported by a strategic ability contributes to a better policy management and implementation.

The general topics included in this article are: 1. Growth theory and regional policy background, where the significance of management and the public policies for the main growth theories and regional policy are emphasized; 2 . Public management, ability and intergovernmental management, in additon to examining the general background of public management and defining the concept of government ability and its impact on the regional development, and 3. Border problems and new approaches in regional development management Some limitations in government ability are analyzed, and, in this context, new management strategies and local policies are proposed.

Key words: intergovernmental management of policies, strategic ability, regional development, effective cooperation, growth theories.

\section{Introducción}

Este artículo tiene el propósito de examinar el papel de los gobiernos locales en el desarrollo regional de la frontera norte mexicana y en un contexto transfronterizo. Los temas centrales del análisis son la capacidad y la gestión intergubernamental en el diseño e im- 
plantación de políticas públicas. ${ }^{1}$ Los gobiernos locales se enfrentan a problemas de índole fronteriza y transfronteriza que corresponden a los ámbitos local, estatal, federal y binacional. En los últimos años, se han agudizado los problemas de migración indocumentada, cruces fronterizos, narcotráfico, inseguridad pública, drogadicción, desarrollo económico, infraestructura ina decuada, deterioro ecológico y procesos de transculturación, entre otros. Tales problemas han influido en los niveles de desarrollo en los municipios del norte de México. Por tanto, la pregunta es: ¿cuáles son las capacidades de los gobiernos locales del norte de México para reducir los efectos negativos de los problemas fronterizos?

La gestión de los asuntos fronterizos implica la participación de los tres niveles de gobierno en México, lo que conlleva el diseño e implantación de políticas intergubernamentales en el pla no naciona. En cambio, la gestión transfronteriza del desarrollo regional significa la consideración de tres esferas gubernamentales en el lado de Estados Unidos, si se considera que las políticas de esos actores provocan impactos en el lado mexicano. Ambos ámbitos de interacción determinan la necesidad de una gestión intergubernamental nacional y transnacional. La complejidad de la gestión intergubernamental en esos dos ámbitos ha influido en los niveles de desarrollo fronterizo. Por ello, una aportación de este artículo es fundamentar que la gestión del desarrollo regional en la frontera norte de México está sujeta a las políticas que formulan los actores locales, estatales y federales en Estados Unidos. En ese contexto, es indispensable valorar el impacto de esas políticas y, en su caso, gestionar binacionalmente los problemas que afectan el desarrollo local-regional en la

\footnotetext{
${ }^{1}$ Tradicionalmente, la bibliografía sobre gobiernos locales en México ha enfatizado sus limitaciones para fomentar una gestión eficaz de los recursos y facultades municipales. El análisis de las variables estadounidense (transfronteriza) y la gestión intergubernamental en los ámbitos local y regional en la frontera norte mexicana añade una mayor complejidad en los procesos de toma de decisiones en el desarrollo regional en México.
} 
frontera norte mexicana. Por ello reviste importancia el fomento de capacidades en términos de profesionalización de los recursos humanos y, en general, capacidades de los gobiernos en el diseño y desarrollo de políticas.

El argumento central de este artículo es que una mayor y eficaz cooperación entre los tres ámbitos de gobierno en materia de desarrollo regional y sustentada en una capacidad gubernamental puede coadyuvar a una mayor eficacia y eficiencia en las políticas de desarrollo fronterizo y transfronterizo. ${ }^{2}$

\section{Antecedentes de las teorías del crecimiento y de política regional}

Gestión pública y teorías del crecimiento económico

En esta sección se examinan el contexto y algunos elementos del papel de la gestión y las políticas públicas en las teorías del crecimiento y de la política regional. El papel de la gestión y las políticas públicas ha sido importante en el debate teórico de las distintas tendencias de crecimiento económico. Sin embargo, la gestión de las políticas de desarrollo regional en países en vías de alcanazar éste ha tenido limitaciones. En varios de los casos, no se han adaptado correctamente las propuestas de cambio en la gestión y en las políticas públicas. Se han reproducido tendencias hacia el control,centralismo, corrupción y procesos de toma de decisiones, donde predominan la jerarquía y una escasa flexibilidad.

La preocupación por hacer frente con políticas públicas a los problemas urbano-regionales, tuvo relevancia en las discusiones y en las propuestas sobre crecimiento y desarrollo planteadas en los años posteriores a la Gran Depresión de 1929. La experiencia efec-

2 La variable transfronteriza (transnacional o estadounidense) tiene importancia en el desarrollo regional fronterizo mexicano, a causa de la interdependencia 0 asimetría que existe entre los diferentes problemas fronterizos de México y Estados Unidos. 
tuada por la TennesseeValley Authority en la cuenca del río Tennessee en Estados Unidos ha sido uno de los ejemplos internacionales más importantes. En esos años, se consideraba que para superar las desigualdades interregionales era necesario impulsar el desa rrollo de las regiones más pobres y que, para ello, el crecimiento económico era una condición necesaria.

Según Richardson (1973:1), "no ha habido preocupación por problemas regionales hasta fines de la década de los 20 y los 30 $y$, aun entonces, ese interés era más bien secundario a la cuestión del crecimiento regional". En el caso de los países latinoamerica nos, la política regional como tal comenzó a esbozarse después de la Segunda Guerra Mundial, hasta alcanzar su máxima expresión en la década de los sesenta. Si se analiza este proceso a la luz de las teorías y de los modelos que marcaron las políticas regionales y urbanas, 9 pueden delimitar tres periodos principales: keynesiano, neoliberal y endógeno (véase cuadro 1). 3

En el enfoque keynesiano, la intervención estatal, tanto directa como indirecta, estaba orientada a promover el crecimiento económico; para ello se requerían políticas específicas para impulsar el crecimiento regional. Las ideas de la CEPAL tuvieron una influencia importante ya que su argumento central parte de que la planificación del desarrollo económico y social es un medio para superar los principales problemas de la región. Se asignaba al Estado un papel central en el diseño y aplicación de la política para promover el desarrollo económico y social. Como consecuencia, durante los años sesenta se multiplicaron las oficinas de planificación y elaboración de planes nacionales de desarroIlo. Surgen entonces los intentos de planificación regional, cuyos criterios y lineamientos básicos tenían sus fundamentos en los modelos de crecimiento keynesiano y postkeynesiano (De Mattos, 1997:4).

\footnotetext{
3 No es el propósito de esta sección evaluar tales enfoques a la luz de los cambios del contexto global y los desequilibrios que se han presentado en páses latinoamericanos. La idea fundamental es ilustrar el marco conceptual en que se ubicaban las propuestas de gestión y de políticas públicas.
} 


\section{Cuadro 1}

\section{Teorías del crecimiento y tipo de política regional}

\begin{tabular}{|l|l|l|}
\hline Modelo & Tipo de regulación & Principales políticas \\
\hline Keynesiano & $\begin{array}{l}\text { Activa: intervención estatal, } \\
\text { tanto directa como indirecta, } \\
\text { orientada a promover d } \\
\text { crecimiento económico; } \\
\text { se requieren políticas } \\
\text { específicas para impulsar el } \\
\text { crecimiento regional. }\end{array}$ & $\begin{array}{l}\text { Políticas públicas imperativas } \\
\text { (inversión y empresas } \\
\text { públicas) e indicativas (incen- } \\
\text { tivos,subsidios, } \\
\text { precios,aranceles,etcétera) } \\
\text { diferenciadas sectorial y } \\
\text { territorialmente }\end{array}$ \\
\hline Neoliberal & $\begin{array}{l}\text { Pasiva: Estado neutral y } \\
\text { subsidiario vela por el libre } \\
\text { juego de las fuerzas del } \\
\text { mercado y asegura el orden } \\
\text { económico monetario } \\
\text { y fiscal, interfiere sectorial } \\
\text { pero no interion } \\
\text { o regionalmente. }\end{array}$ & $\begin{array}{l}\text { Políticas de liberalización } \\
\text { económica y de desregulación } \\
\text { orientadas a asegurar el libre } \\
\text { juego de las fuerzas del } \\
\text { mercado; no se considera } \\
\text { necesario aplicar políticas } \\
\text { regionales específicas } \\
\text { de carácter general. }\end{array}$ \\
\hline $\begin{array}{l}\text { Crecimiento } \\
\text { endógeno }\end{array}$ & $\begin{array}{l}\text { Intermedia: regulación con el } \\
\text { propósito de generar un } \\
\text { ambiente atractivo para la } \\
\text { inversión privada, } \\
\text { incluyendo políticas para } \\
\text { promover el crecimiento } \\
\text { regional. }\end{array}$ & $\begin{array}{l}\text { Políticas públicas buscan } \\
\text { asegurar gestión de } \\
\text { externalidades y provisión de } \\
\text { bienes públicos, garantizar } \\
\text { derechos de propiedad } \\
\text { intelectual y física, } \\
\text { regular sector financiero y } \\
\text { relaciones económicas } \\
\text { externas, eliminar distorsiones } \\
\text { económicas y mantener } \\
\text { marco legal garante del } \\
\text { orden público; política } \\
\text { regional orientada a activar } \\
\text { el potencial endógeno del lugar. }\end{array}$ \\
\hline
\end{tabular}

Fuente: CarlosA. de Mattos (1997).

En la medida en que esos fundamentos consideraban que $\mathrm{d}$ juego de las fuerzas del mercado no aseguraba la convergencia interregional, se multiplicó el número de estrategias con propuestas de industrialización periférica y de polos de crecimiento, como vía para promover el crecimiento ( $y / 0$ desarrollo) de las regiones pe- 
riféricas. En este marco, el papel del Estado era fundamental en términos de conceder incentivos y desincentivos fiscales y financieros,subsidios, tarifas y precios diferenciales,controles,empresas públicas ( véase cuadro 1).

A la luz de esta concepción de planificación urbano-regional se crearon los primeros programas de enseñanza en este campo. La idea era formar a los planificadores regionales y urbanos que debían hacerse cargo de elaborar las estrategias, políticas y progra mas de desarrollo regional y urbano. En esos años, se tenía la certeza teórica de la manera de elaborar dichos programas. Según De Mattos (1997:6), la confianza total en los enfoques de planifica ción del desarrollo como alternativa para fomentar el crecimiento, ha caracterizado los programas de enseñanza en la materia, particularmente en América Latina.

Sin embargo, el fracaso de la planificación del desarrollo y la crisis de las ideas y las recetas voluntaristas e intervencionistas afectaron la gestión urbana y regional y, consecuentemente, a los respectivos programas de enseñanza. A pesar de ello, aún existen influencias del modelo keynesiano en la orientación y contenido en varios posgrados de América Latina y en algunos países desa rrollados (De Mattos, 1997:6). Es una situación que obedece a que se sigue considerando que los planteamientos teórico-metodológicos en materia de planificación del desarrollo regional y urbano son aún relevantes, no obstante de que al momento de contrastarlos o incorporarlos con programas concretos o políticas públicas han resultado obsoletos. Dichos planteamientos no corresponden a los cambios sociales, económicos, institucionales que experimenta cada país. Se presenta un problema de desvinculación entre teoría y práctica, lo que refleja una escasa visión integral y objetividad de los analistas regionales sobre las limitaciones de los enfoques de planificación del desarrollo regional-urbano.

El enfoque liberal-neoclásico surge en un marco en que se agotan los proyectos desarrollistas de corte keynesiano, y sobre todo la posibilidad de crear una sociedad alterna al capitalismo. A 
principios de los años sesenta datan los antecedentes de la aplica ción del enfoque de políticas públicas en materia de desarrollo regional. Uno de los teóricos principales de ese enfoque fue Charles Lindblom (1991), 4 cuya perspectiva del incrementalismo inconexo, y los desarrollos de la escuela de la elección pública tuvieron influencia. Desde otra vertiente teóricaideológica, los aportes de Simon (1957) sobre racionalidad limitada en los procesos decisionales sociales, fueron también determinantes en las nuevas concepciones de políticas públicas. En este enfoque, se concebía que los procesos sociales son modulados por una multiplicidad de actores, que deciden y actúan motivados por diversos valores, intereses y demandas, recurriendo a estrategias frecuentemente contradictorias entre sí. De esta manera, se ha aceptado que la capacidad humana es ilimitada para decidir y actuar en el marco de sistemas sociales de complejidad creciente, por lo cual sólo puede desenvolverse conforme a una racionalidad procesal (De Mattos, 1997:7). Estos enfoques se adoptaron con mayor énfasis en países desarrollados. En cambio, en países en desarrollo, si bien también predominó un papel central del Estado y sus gobiernos, tradicionalmente han existido problemas de centralismo y limitados consensos entre los distintos actores en el diseño de las políticas.

El enfoque neoliberal asociado al ámbito económico significa que la evolución de los procesos económicos regidos por el libre

\footnotetext{
4 Según Lindblom, el comportamiento de los decisores se basa en ajustes marginales sobre políticas en marcha. El modelo incremental es más descriptivo que prescriptivo y se basa en el comportamiento cotidiano de los que toman las decisiones. Desde su perspectiva, las políticasse elaboran a través de los distintos mecanismos mediante los que la gente ejerce control, influencia o poder sobre otros. Es la interacción política entre los individuos y los grupos sociales el factor que más condiciona la ela boración de políticas públicas. El modelo incremental de Lindblom argumenta que las decisiones sobre las políticas son, ante todo, pragmáticas, no se basan en relaciones causales bien estudiadas, ni en cálculos exhaustivos de costos y beneficios, sino en el método de las aproximaciones sucesivas y limitadas. Es decir, el que decide sólo toma en consideración aquellas alternativas que difieren muy poco de las políticas efectua das, rechazando las demás, y analiza sólo los aspectos en que la opción nueva y sus consecuencias difieren de la situación actual, obviando el resto.
} 
juego de las fuerzas del mercado conduciría a una mayor convergencia. Desde este planteamiento, la existencia de voluntad política y capacidad eran indispensables para promover políticas tales como: una liberalización económica que favorezca las fuerzas del mercado, una reforma del Estado orientada por los principios de subsidiariedad y de neutralidad y una amplia apertura externa que permita integrar mercados a escala mundial.

En materia de gestión del territorio, se dio por sentado que para superar los desequilibrios interregionales no se requería de una política regional (véase cuadro 1). Se suponía que en un contexto en el que las fuerzas del mercado actúan libremente, no sería necesario recurrir a instrumentos específicos de política pública, pues podrían interferir en la convergencia y un mayor equilibrio interregional. En concreto, las políticas públicas debían orientarse a ayudar al mercado para alcanzar la convergencia.

El enfoque del crecimiento endógeno surge en un contexto en que la dinámica capitalista indicaba divergencias en sus procesos de crecimiento, especialmente en economías con niveles de desarrollo desiguales $5 \mathrm{Si}$ bien el enfoque endógeno no está constituido como un todo integral, parte de un eje central, es decir, la tasa de crecimiento depende básicamente de tres factores: capital físico, capital humano y conocimientos, que se pueden acumular y generan efectos secundarios. Por tanto, la función principal de la política económica es contribuir a generar un ambiente atractivo para la inversión privada En tal enfoque se descarta la intervención directa del Estado en la economía Por tanto, la gestión y las políticas públicas favorecen una gestión endógena como medio para activar el potencial de cada territorio. Su objetivo central es aumentar su competitividad a través de promover empresas más innovadoras.

Como se puede apreciar, el papel del Estado, la gestión y las políticas públicas han sido importantes en las teorías de crecimiento regional y las políticas regionales (véase cuadro 1). Su pa-

5 Un análisis interesante sobre las teorías del crecimiento regional lo desarrolla Cuadrado (1995). 
pel ha dependido del modelo adoptado por los estados en el desarrollo de sus políticas regionales.

La importancia del papel de los gobiernos y las administraciones públicas en materia de política regional también ha sido pues ta de manifiesto por uno de los principales estudiosos del tema en el ámbito internacional, como es el profesor Harry W. Richardson (1975). Desde su perspectiva, el papel de los gobiernos y las administraciones públicas es fundamental en el diseño, formula ción, implementación y planeación de las políticas y desarrollo regional, especialmente en países en desarrollo. ${ }^{6}$

Entre los argumentos centrales para fundamentar una mayor participación de la gestión y las políticas públicas, se encuentra el hecho de que los planes y programas de desarrollo regional son formulados o puestos en práctica por los gobiernos y administra ciones públicas. Según Keating (1993), la administración de la política regional está en la posición de asumir un papel estratégico en la siguiente forma: 1) asignando los recursos públicos (subvenciones, créditos, programas de financiación conjuntos, etcétera); 2) participando en la planificación estratégica para va lorar y dar prioridad a las necesidades de la región a través de una estrategia común, y 3) trabajando en redes de un nivel superior dentro de la estructura institucional para conseguir el acceso a una financiación adicional y para crear alianzas estratégicas. Desde la perspectiva de la política regional, uno de los temas importantes es el papel de los agentes que toman las decisiones de actuación y la manera en que las ejecutan. En ese contexto, la organización política e institucional de las relaciones entre los

\footnotetext{
6 Actualmente el profesor Richardson está adscrito a la School of Policy, Planning, and Development, University of Southern California.Dicha escuela es una fusión de las escuelas de Administración Pública y de Planeación Urbana y Desarrollo. La escuela hace hincapié en las áreas de políticas: análisis de los procesos de toma de decisiones, sobre todo en las políticas de descentralización y en la gestión en los sectores público, privado y social. Otro campo es el de la planeación, donde se enfatizan los temas urbanos y regionales, y, por último, la esfera de desarrollo, con respecto a vivienda, transporte, empleo, crecimiento económico en un enfoque sustentable.
} 
distintos niveles de autoridad y los problemas de coordinación resultan de especial interés (Cuadrado, 1988:69).

\section{Gestión pública, capacidad y gestión intergubemamental}

Antecedentes en el cambio del Estado y la gestión pública

En esta sección se examinan algunos antecedentes generales de la gestión pública, con la finalidad de destacar sus principales aportes en las políticas de desarrollo regional.

Desde la década de los treinta, en la mayor parte de los países capitalistas la concepción del Estado evolucionó hacia el modelo del Estado providencia. Se ampliaban las responsabilidades estata les hacia la oferta de bienes públicos básicos. Su principal función radicaba en lograr la cobertura de esos servicios; aunque se mantenían los preceptos legales, los procedimientos administrativos y la teoría de la burocracia (Cabrero, 1998:20)

En la segunda mitad del siglo xx, el enfoque jurídico tradicional de la administración pública comienza a perder su capacidad para explicar los cambios en el entorno. Así comenzaba a ampliarse la intervención estatal hacia diversos sectores de la actividad. Esta etapa se caracteriza por un cierto retroceso de la norma jurídica, adquieren más importancia los consensos de los actores políticos para promover el desarrollo económico. Es la etapa del Estado omnipresente. No obstante, los distintos niveles de desarrollo de los Estados y la dificultad de reducir la influencia de los preceptos institucionales dieron pie a que coexistieran ejes de ambos enfoques.

La alta complejidad en que se veían inmersas las estructuras gubernamentales generaba la necesidad de crecer en tamaño, pa ra intentar enfrentarse a dicha complejidad. El monopolio estatal se fragmenta. La lógica de la acción gubernamental se diversifica en varias lógicas. Una de ellas es una mayor interacción con agentes $y$ agencias gubernamentales. 
La nueva realidad se caracteriza por un escenario de interacción de actores, de variables exógenas que alteran el funciona miento de las dependencias y las obligan a desarrollar capacidades adaptativas. En esta coyuntura, los gobiernos y las administraciones públicas tienen necesidad de legitimarse por sus rendimientos, por su desempeño y no únicamente porque son autoridades.

Es entonces, a fines de los años cincuenta y a lo largo de los sesenta, cuando surge la escuela de las políticas públicas (Aguilar, 1992) como un marco de análisis. Este enfoque analizaba la acción gubernamental con otra óptica, dejando de lado varios supuestos básicos de la administración pública: al análisis que se funda en la dependencia se contrapone el análisis que parte de la política pública en cuestión; a la norma jurídica como base de estudios se contrapone el proceso decisorio; al acotado campo de la administración se opone la amplia gama de vínculos e intersecciones entre los ámbitos político y administrativo (Cabrero, 1998:21). Sin embargo, los distintos niveles de desarrollo entre los Estados dificultan que las orientaciones de las políticas públicas se puedan aplicar de manera homogénea. De hecho, pueden coexistir tendencias - democrática y autoritaria - en cadauna de las etapas del proceso de políticas (formulación, elección, implantación y evaluación). Estas etapas cambian en función del tipo de política: distributiva, redistributiva y regulativa, según el contexto.

Una vez que el Estado omnipresente entra en una profunda crisis de legitimidad a fines de la década de los setenta, se inicia nuevamente la reconfiguración del aparato estatal. Son los años del auge neoliberal. Surge lo que se ha dado en llamar el Estado modesto (Crozier, 1987) o el Estado regulador, comprometido en la articulación de los esfuerzos del conjunto de los actores, y deja de lado la tentación de atender directamente con dependencias propias todos los asuntos públicos. Se plantea la necesidad de que las dependencias sepan funcionar, sobrevivir, ser autosuficientes, con altos grados de profesionalización (Cabrero, 1998:22). De ahí la importancia que adquiere la toma de decisiones, la visión estraté- 
gica, el juego de actores, los problemas de eficiencia, las preferencias del cliente-usuario. En ese contexto surgen la gestión y la gerencia pública.

Se parte del supuesto de que un buen gobierno será aquel en que el conjunto de redes de dependencia funcione bien; es decir, con eficiencia en el ejercicio de los fondos públicos, con eficacia en la interacción con agentes y agencias externos, y con legitimidad en la prestación del bien o servicios que produce (es decir, la satisfacción al cliente y la rendición de cuentas) (Barzelay, 1992).

Los elementos de la gestión pública, y en especial la modernización, en países latinoamericanos constituyen un problema mucho más amplio, es decir, es un problema de cambio político, social, económico y de gestión pública. Mientras que en países desarrollados la modernización de las dependencias gubernamentales es un problema de gestión pública (Cabrero, 1998:30). No obstante, el papel gubernamental está condicionado por el modelo económico prevaleciente y, en consecuencia, por el papel asignado al Estado.

En suma, los problemas de gestión pública en países latinoa mericanos no sólo tienen que ver con un mejor desempeño gubernamental, sino también, sobre todo, con un problema de gobernabilidad. Es decir, la gestión pública en países en desarrollo se enfrenta a problemas complejos: generar eficiencia,eficacia y legitimidad, simultáneamente (Cabrero, 1998:33).

Una nueva gestión pública: algunos elementos

El enfoque de la nueva gestión pública7 deriva de dos tendencias en la administración pública contemporánea: uno, la revaloriza ción de la naturaleza pública del gobierno y de la administración, que se caracteriza por la revalorización del Estado de derecho y la democratización del régimen.Y una segunda tendencia, referida a la renovación de la capacidad administrativa del gobierno y de la

7 Para profundizar sobre los antecedentes de ese enfoque, véase Olías de Lima (2001) y Lynn (1998). 
administración pública. Sus antecedentes principales son la crisis fiscal y administrativa del Estado, la liberalización (cambio estructural) de la economía, la globalización y la nueva economía y la agudización de los impactos sociales (Aguilar, 2002).

En el marco en que se pretende renovar el papel del sector público para promover su legitimidad por rendimientos, se ha planteado cambiar la naturaleza pública del gobierno y de su administración. El contexto del cambio radica en que las administra ciones públicas y los gobiernos se legitiman por sus rendimientos, es decir, por lo que hacen y cómo lo hacen. Por tanto, es fundamental enfocar con precisión los objetivos de la gestión y de la acción de gobierno, fomentar el desempeño institucional y los procesos de innovación bajo un sentido social. El planteamiento se justifica porque el enfoque institucional de la administración pública ha tenido limitaciones para aprehender la complejidad de administrar, negociar y establecer consensos entre los distintos actores ante nuevas demandas sociales, los cambios en el entorno cultural, recursos económicos escasos, un contexto político plural y, fundamentalmente, la complejidad que reviste el desarroIlo regional.

La renovación de la capacidad administrativa del gobierno significa finanzas públicas sanas, eficiencia económica, dirección estratégica, dirección de la calidad, dirección del conocimiento y la profesionalización del servicio público. En ese marco, la importancia de la gestión radica en promover y dirigir políticas orientadas hacia una mayor calidad de la administración pública. Sus orientaciones son la calidad institucional y la calidad gerencial.Esto representa un salto cualitativo de la administración pública orientada hacia su entorno, en busca de promover un mayor va lor para los ciudadanos y su comunidad, es decir, crear valor público (Aguilar, 2002).

En un entorno social y cultural diverso, complejo y globaliza do, la gestión del desarrollo regional debe orientarse hacia procesos de cambio con el objeto de fomentar la eficacia, la eficiencia y la efectividad. Con esa óptica, la capacidad gubernamental es in- 
dispensable en la reformulación de los procesos de gestión del desarrollo regional y en general de las políticas públicas.

Desde una perspectiva local, el desarrollo responde a las sguientes prioridades:

- Estimular el crecimiento económico a partir de políticas de empleo, de fomento de los beneficios empresariales 0 de distribución de ventajas impositivas.

- Generar el liderazgo y orientación de un entorno cada vez más cambiante y turbulento.

- Minimizar la vulnerabilidad de las economías locales frente a las fuerzas exteriores del mercado (Brugué y Gomá, 1998c:121).

En materia de políticas de promoción económica, la relación del gobierno con el sector empresarial es fundamental. La interacción es definida como un acuerdo entre grupos de interés, organizaciones y/ 0 instituciones que conlleva la coordinación de los elementos anteriormente señalados (competitividad, previsión estratégica y liderazgo) en el marco de las iniciativas locales. Además, también participan el resto de los actores relacionados con la promoción económica y el desarrollo, como son el sector social. Al margen de las peculiaridades de los distintos tipos de acuerdos público-privado, parece una opinión generalizada que tal interacción representa la mejor fórmula para crear programas de desarrollo local y regional. Una iniciativa local que pretenda estimular los recursos estratégicos de su territorio debería articularse a través del potencial y el aprovechamiento de redes de cooperación formadas por los diversos actores económicos locales (véase cuadro 2).

En resumen, los territorios con mayores probabilidades de éxito económico son los que movilizan los actores públicos o privados y que son capaces de estimular sus recursos estratégicos y, de este modo, aprovechan las oportuni dades de la globalización económica (Brugué y Gomá, 1998c:124). Es pertinente mencionar que en el caso de los países en desarrollo, los gobiernos locales $s$ 


\section{Cuadro 2}

Instrumentos para aprovechar el potencial de la comunidad local

\begin{tabular}{|l|l|l|}
\hline Objetivos & Métodos & Organización \\
\hline $\begin{array}{l}\text { Construir organizaciones } \\
\text { en el nivel local }\end{array}$ & $\begin{array}{l}\text { Organizar a la comunidad } \\
\text { y formar negocios }\end{array}$ & $\begin{array}{l}\text { Corporaciones para el } \\
\text { desarrollo comunitario }\end{array}$ \\
\hline $\begin{array}{l}\text { Impulsar el control por } \\
\text { parte de trabajadores } \\
\text { y empresarios locales }\end{array}$ & $\begin{array}{l}\text { Empresas de } \\
\text { carácter colectivo }\end{array}$ & $\begin{array}{l}\text { Cooperativas } \\
\text { comunitarias }\end{array}$ \\
\hline $\begin{array}{l}\text { Lucha comunitaria } \\
\text { contra el paro }\end{array}$ & $\begin{array}{l}\text { Movilización de } \\
\text { recursos locales }\end{array}$ & $\begin{array}{l}\text { Agencias locales de } \\
\text { ocupación }\end{array}$ \\
\hline $\begin{array}{l}\text { Desarrollar los recursos } \\
\text { humanos del territorio }\end{array}$ & $\begin{array}{l}\text { Iniciativas locales } \\
\text { de formación }\end{array}$ & $\begin{array}{l}\text { Comisión local para la } \\
\text { formación y la ocupación }\end{array}$ \\
\hline
\end{tabular}

Fuente: Brugué y Gomá (1998c:131).

enfrentan a la dificultad de crear acuerdos con el sector privado, si se pretende reducir sus prioridades económicas, favoreciendo un mayor impacto social. En otros contextos locales, los convenios entre el sector privado y el sector público y social se suscriben tratando de equilibrar las prioridades empresariales, sociales y gubernamentales. Se supone que en la medida en que exista tal equilibrio, los participantes obtienen beneficios acordes a sus prioridades. Recurrir a tal concepción en las políticas públicas tiene que ver con un gobierno con capacidad y visión estratégica.

De esta concepción deriva la importancia del fortalecimiento institucional, que se concibe como una herramienta para la gestión asociada y el trabajo de alianza con el conjunto de los actores. Las dimensiones de análisis para el fortalecimiento institucional son: la capacidad asociativa, la capacidad de influencia en las políticas que atiendan las problemáticas en las que se interviene, la capacidad de anticipar temas y transferir modelos de intervención y finalmente, la capacidad de planificación y gestión (Clemente, 2000:124). 
Capacidad gubernamental y políticas de desarrollo regional

Se plantea como punto de partida el hecho de que los gobiernos de los estados fronterizos del norte de México carecen de capacidad gubernamental para fomentar una gestión eficaz del desarrollo regional. 8 La capacidad gubernamental alude a que: "[...] un gobierno puede prever ejercer influencia sobre los cambios; adoptar decisiones políticas informadas e inteligentes; captar, absorber y gestionar recursos, y evaluar actividades actuales a fin de orientar la actividad futura" (Agranoff, 1997:151).

Por su generalidad, el concepto de capacidad en los estudios de políticas y gestión pública ha tenido dificultades para su operacionalización (Agranoff y McGuire, 1998). Según estos autores, se mantiene una discusión sobre el término de "capacidad", pues se conoce que existe, pero no se sabe exactamente qué es y aunque existen algunas definiciones 0 características, se ha empleado algunas veces de manera frívola. En cambio, el término de capacidad es un concepto más común en la bibliografía sobre desarrollo urbano y rural. En estos casos, la capacidad se asocia al desarroIlo local, en términos de la capacidad de los gobiernos locales (Vogelsang-Coombs y Miller, 1999). Igualmente, $s$ concibe que la "construcción de la capacidad" es una parte importante del dise ño de una política efectiva (Agranoff et al., 1994).

Una de las críticas al concepto de capacidad es su orientación hacia la solución de problemas concretos, hacia el saber hacer, hacia la formación de practitioners (profesionales). Este tipo de respuesta corresponde a los requerimientos de una sociedad excesivamente privatizada. Se piensa que esta opción muchas veces termina trasmitiendo "soluciones" o paradigmas de moda, de

\footnotetext{
8 Esta afirmación se pretende fundamentar en la importancia que han adquirido algunos problemas fronterizos y en el análisis de algunas limitaciones de los gobiernos locales y estatales de la frontera norte mexicana, en términos de su capacidad gubernamental y de gestión de políticas para promover el desarrollo regional. No se busca generalizar al conjunto de los gobiernos fronterizos tal limitación.
} 
eficacia no probada, que supuestamente permitieran resolver problemas para los que todavía no hay respuestas claras.

Otro de los problemas del concepto de capacidad radica en el enfoque empleado y en la manera en que se articula con otros planteamientos de cambio en la gestión pública. Por ejemplo, según Luis F. Aguilar (2002), la capacidad administrativa en términos de renovación hace alusión a finanzas públicas sanas, dirección financiera, eficiencia económica, dirección estratégica, dirección de la calidad, dirección del conocimiento y la profesionalización del servicio público.

Otra concepción que complementa el examen de la capacidad es la noción estratégica de Dror (1995 y 1997), orientada hacia una mayor eficacia en la planeación y el desarrollo regional.Algunos de los elementos de esta capacidad estratégica son la profesionalización y la cultura de gestión y de gobernar. Con respecto al enfoque de políticas, se alude a la importancia de elaborar políticas concretas, la asimilación e intercambio de experiencias, definición de cuestiones críticas, la creatividad en el rediseño de políticas, comprensión de los procesos históricos, consideración del entorno y su impacto en la visión de futuro, la definición de perspectivas de largo plazo, la valoración de la incertidumbre y el papel de los recursos humanos y financieros $y$, finalmente, establecer una gestión orientada a prever las tensiones y conflictos. Todo esto en un marco en que las organizaciones públicas se conciben bajo un constante aprendizaje institucional.

Como se puede apreciar, el concepto de capacidad tiene distintas connotaciones, acorde con el tipo de área de estudio. En este artículo se utiliza la definición de Agranoff (1997:151), según la cual la capacidad gubernamental radica en "prever ejercer influencia sobre los cambios; adoptar decisiones políticas informadas e inteligentes;captar, absorber y gestionar recursos, y evaluar actividades actuales a fin de orientar la actividad futura" Entendida la capacidad como tal, se espera que los gobiernos con mayor capa cidad mejoren la gestión de sus programas. Según el propio Agra noff (1997), el aumento de la capacidad es el objetivo de muchos 
programas de desarrollo de liderazgo y de la gestión intergubernamental. Por ejemplo, para promover el desarrollo local, se recomienda la planificación estratégica, el análisis de datos complementarios, la elaboración de datos comunitarios y el desa rrollo de las instituciones; es decir, ayudar a crear y apoyar a los organismos de desarrollo económico y comunitario. Otra estrategia para promover la capacidad la representan los programas de modernización. Su objetivo generalmente es fomentar las capacidades en los ámbitos nacional y regional en áreas tales como: estrategias y técnicas administrativas, la renovación y motivación de los recursos humanos y el desarrollo de los principios de la gestión del área funcional.

Un estudio deTimothy Mead (1981) sobre varias ciudades de Estados Unidos logró identificar seis procesos asociados a los niveles elevados de capacidad:

- Las personas competentes ocupan tanto cargos de elección clave como administrativos, y existe continuidad sustancial entre los últimos

- Las prácticas de gestión fiscal se utilizan como herramientas de políticas que permiten planificar y controlar el capital y las operaciones.

- Los empleados públicos reconocen la legitimidad de la preocupación por la igualdad en las políticas públicas y la administración pública.

- Los procesos abiertos de toma de decisiones facilitan el intercambio de puntos de vista entre los ciudadanos y los funcionarios.

- Los servicios públicos $æ$ prestan de manera efectiva y eficiente.

- Se utilizan sistemas de gestión de la información que faciliten flujos de toma de decisiones entre los sectores políticos y administrativos, y dentro del sector público.

El estudio de Mead es de los pocos análisis sobre capacidad que identifica y compara las prácticas gubernamentales específicas. 
En opinión de Agranoff (1997:152), "aunque en las ciudades más grandes varía la capacidad, el fomento de la misma supone un problema, pero es un problema mayor para los gobiernos de tamaño más reducido". Es decir, la cuestión de la capacidad se ha agudizado en la medida en que la complejidad de la función de un gobierno ha aumentado en términos de las diversas responsa bilidades y las tecnologías necesarias para administrar programas.

La relevancia de la capacidad de los gobiernos locales radica en que a sus tareas meramente operativas y ejecutoras, se suman actuaciones de horizonte estratégico. Los gobiernos locales y regionales pueden definir modelos económicos, sociales y territoriales para sus ciudades. Es decir, cuentan con la capacidad para promover el crecimiento y el desarrollo económico local y regional. El salto cualitativo de los gobiernos locales hacia una perspectiva estratégica, se caracteriza por un modelo de crecimiento con fuertes componentes endógenos. En ese marco, los gobiernos locales pueden impulsar mejor que ningún otro actor público 0 privado los elementos de valorización territorial (suelo, infraestructura) y redes de cooperación y humana (formación continua).

En la perspectiva del desarrollo endógeno, esos elementos son necesarios para garantizar el futuro de las economías locales sujetas a las dinámicas de la competencia global (Brugué y Gomá, 1998). Los gobiernos locales son los que pueden diseñar dichas políticas desde la proximidad, desde el conocimiento de la realidad concreta de cada municipio. Esto abre la posibilidad de definir localmente modelos sociales de ciudad, con opciones públicas de bienestar local más o menos integrales en función de decisiones políticas municipales de claro alcance estratégico. Esta perspectiva es importante para los municipios del norte de México, cuya interacción con Estados Unidos y los efectos que ha provocado el TLCAN en los ámbitos local y regional, obligan a valorar el impacto de las políticas fronterizas estadounidenses. La finalidad es tratar de concebir una estrategia de desarrollo local en un contexto transfronterizo, donde se comparten problemas fronterizos. 
Capacidad gubernamental y condicionantes

El campo de estudio de la gestión del desarrollo regional con una perspectiva transfronteriza, es relevante por el carácter de las rela ciones entre México y Estados Unidos. Y de manera especial, por la vecindad con California y Texas, que son estados de gran desa rrollo económico. Este marco justifica la formación y profesiona lización de la administración pública fronteriza mexicana con una perspectiva transfronteriza. El objetivo es promover el desarrollo regional en un contexto binacional y reducir los impactos locales y regionales de las políticas de Estados Unidos.

La importancia de una administración pública con una visión transfronteriza ha sido destacada por Luis F. Aguilar Villanueva (1996) en los siguientes términos:

[...] la administración pública de estados, municipios y regiones fronterizas aumenta su visión estratégica y el impacto de sus acciones si incorpora sustantiva y permanentemente, en su conceptualización e iniciativas, las potencialidades de la comunicación y cooperación transfronterizas [...].

En términos operativos, la capacidad de los gobiernos locales se relaciona con los instrumentos jurídicos y administrativos que pueden potenciar su acción sobre el desarrollo local y regional.

La capacidad gubernamental está sujeta a condicionantes externos e internos. Los primeros se asocian al marco jurídico, el federalismo, la descentralización y las relaciones interguberna mentales. En cambio, los condicionantes internos se refieren a las capacidades de conducción, consenso y articulación con los distintos actores; la estructura administrativa, instrumentos técnicos, finanzas públicas y la eficacia de la gestión; y la reglamentación interna. También deben considerarse el escenario político y social del municipio; sus relaciones con los demás actores locales, internos y externos; los contextos económicos (el modelo de acumulación), social y político en los ámbitos estatal, regional, nacional y mundial (globalización). Aspectos que reflejados en 
el ámbito municipal son determinantes de su acción y, finalmente, los planes, programas y proyectos de desarrollo y sus impactos en el desarrollo regional.

Los elementos anteriores constituyen la capacidad de los gobiernos locales y coadyuvan a promover la cooperación y la pla neación del desarrollo fronterizo desde una perspectiva nacional y binacional. ${ }^{9}$ Otro aspecto a destacar son loscambios que deben tener las organizaciones públicas en un contexto de redefinición de políticas y adaptación a nuevos procesos de toma de decisiones, bajo criterios de eficacia, eficiencia y efectividad. En ese marco, resultaría de interés valorar en qué medida la administración pública mexicana, en sus tres ámbitos de gobiemo, se ha adaptado a la apertura comercial 0 , en general, a la modernización de la administración gubernamental en un plano global.10

En la investigación sobre problemas fronterizos en México, se adolece de estudios que evalúen el papel y la capacidad de los gobiernos de los estados fronterizos en sus relaciones con sus homólogos fronterizos de Estados Unidos. En el caso de este país, uno de los estudios más importantes sobre esa línea de investigación binacional es el de Saint-Germain (1995).11 Entre sus conclusiones, destaca la idea de que una capacidad gubernamental limitada se asocia a una escasa formación profesional y conocimiento de su entorno de los funcionarios públicos de la

9 Cabe mencionar que José Sosa (1999) refiere que la "capacidad gubernamental [...] alude a la suma de recursos humanos, financieros, técnicos y legales con los que una organización pública cualquiera toma decisiones y produce bienes y servicios". Según su punto de vista, "[...] el desarrollo y diversificación de esta capacidad en los gobiernos municipales de la frontera norte es uno de los factores medulares que explican su evolución reciente, particularmente con respecto a las capacidades financieras de estados y municipios fronterizos"(p.126).Se considera que esta definición no se contrapone al concepto de capacidad gubernamental que se ha empleado en este artículo, y que deriva de una definición de Robert Agranoff (1997).

10 Tales aspectos no forman parte del objetivo central de este artículo.

11 El estudio de Saint Germain (1995) se ubica en la perspectiva de la administración pública comparada, que ha tenido un desarrollo importante en Estados Unidos. 
frontera México-Estados Unidos para fomentar la cooperación y la negociación en los asuntos fronterizos con Estados Unidos. ${ }^{12}$ Asimismo, en el estudio de Saint-Germain (1995) se detectaron diferencias importantes en las administraciones de ambos gobiernos locales, particularmente con respecto a las variables de percepción sobre el sector público, educación,nivel de especialización y motivación laboral, las que responden a culturas diferentes en las administraciones públicas de México y Estados Unidos.

El estudio de Saint-Germain fue previo al desarrollo del TLCAN. Sin embargo, mantiene su importancia en términos de su propuesta metodológica para analizar el papel de las administraciones públicas en estados fronterizos. Además, algunos de los problemas estructurales planteados en el artículo de Saint-Germain (1995) siguen estando presentes, pero con otros matices y tendencias en la gestión pública local y regional fronteriza

La gestión intergubernamental de políticas públicas

El énfasis en el papel de las unidades y actores gubernamentales, es propio de un enfoque que examina las actitudes, la interacción, la negociación, la cooperación, la coordinación y el conflicto intergubernamental. Son rasgos que pertenecen a regímenes federales, en la medida en que descentralizan sus procesos de toma de decisiones (Wright,1997). Este análisis es novedoso en la ciencia política y la administración pública en México porque trasciende el análisis tradicional del Derecho Administrativo o el Derecho Público. Son áreas que se han caracterizado por un énfasis en la normatividad institucional, y si bien proporcionan elementos pa-

12 El estudio de Saint-Germain (1995) se limitó a funcionarios públicos de los gobiernos de El Paso, Texas, y Ciudad Juárez,Chihuahua. En el caso de la primera ciudad, se entrevistó a 51 funcionarios municipales relacionados con 35 agencias públicas. En el caso de Ciudad Juárez, se entrevistó a 28 funcionarios municipales, de 22 dependencias públicas. De antemano la propia autora reconoce que no se pretende generalizar los resultados obtenidos al conjunto de las ciudades fronterizas de México y Estados Unidos. Las entrevistas se efectuaron a principios del año de 1993. 
ra una mejor comprensión de las organizaciones políticas, el desarrollo de la democracia ha provocado otros problemas. Por ejemplo, la cooperación intergubernamental para promover políticas eficaces en el contexto del federalismo y la descentralización; el impacto de los procesos de integración económica en las rela ciones intergubernamentales (Hooghe, 1996); la gestión intergubernamental del conflicto en un marco de constantes demandas sociales y de los grupos de presión; el entorno político de las organizaciones públicas para fomentar el desarrollo y la competitividad. Finalmente, la gestión intergubernamental transfronteriza de problemas como el de inseguridad pública, narcotráfico, el medio ambiente y en general del desarrollo regional en la frontera México-Estados Unidos.

Tradicionalmente la gestión de políticas públicas entre distintos ámbitos de gobierno y actores, no había formado parte del análisis académico en México. ${ }^{13}$ Se debe a dos razones fundamentales. por un lado, otras prioridades en el análisis del Estado, el tipo de gobierno y la administración pública en México y, por otro, la concentración de decisiones y políticas en el gobierno federal. La tendencia a la centralización era uno de los componentes estructurales de la relación entre los gobiernos federal, estatal y local.

Los avances en la democratización del país en los últimosaños, han influido para lograr una mayor descentralización administra tiva. Esto ha permitido que los ámbitos de gobierno tengan necesidad de coordinarse administrativamente y, en esencia, fomentar acuerdos de cooperación intergubernamental con el fin de gestionar eficazmente las políticas descentralizadas. ${ }^{14}$

13 Un indicador del incipiente estudio sobre las relaciones intergubernamenta les en México es que en el año de 1997, se tradujo al castellano uno de los principa les textos sobre el tema, como es la obra de Deil W right (1997).

14 Entre los antecedentes de relaciones intergubernamentales en México, cabe mencionar que en 1980, se introdujo, por un lado el Convenio Único de Coordina ción (CUC), instrumento jurídico que formalizaba las relaciones intergubernamenta les en el marco de las políticas de desarrollo de los estados y, por el otro, el Sistema Nacional de Coordinación Fiscal (SNCF), instrumento de coordinación interguberna mental orientado a promover el uso racional y la distribución equitativa de los recur- 
Los Comités Promotores de Desarrollo de los Estados (Coprodes) y el Convenio Ú nico de Coordinación (CUC), son los antecedentes inmediatos de la gestión intergubernamental en la planeación del desarrollo en México. Durante una década de existencia, el cuc se ha consolidado como el principal instrumento jurídico, administrativo, programático y financiero de la coordinación intergubernamental en la planeación del desarrollo regional en México. En este sentido, existe una coordinación administrativa, la cual puede ser insuficiente para gestionar políticas en donde participan diferentes actores, que adoptan diferentes posiciones de tipo político, social y económico.

Se puede afirmar que el estudio de las relaciones intergubernamentales está en proceso de desarrollo en México y se requiere una sofisticación de sus instrumentos. Especialmente con respecto a los asuntos de subvenciones intergubernamentales, las regulaciones, órganos de negociación, formulación e implantación de políticas y el manejo de técnicas y en general, una gestión conjunta de políticas y programas. Estos temas han sido poco analizados desde el punto de vista académico en México. Entre otras causas por el incipiente proceso de democratización nacional y la mayor importancia que se ha adjudicado a los temas de la gobernabilidad y la democratización y a la gestión de los procesos de descentralización.

En los próximos años el federalismo mexicano tendrá que revisarse política y jurídicamente, porque los gobiernos locales del norte de México se enfrentan a problemas de carácter federal,como la migración laboral, el narcotráfico y la contaminación ambiental, que cuestionan su propia legitimidad y el desarrollo local y regional. 15 La pregunta central es: ¿cómo pueden los gobiernos

sos públicos en toda la nación. Para un mayor análisis de antecedentes de coordina ción intergubernamental en México, véase Aguilar (1996).

15 En noviembre de 1999, se reunieron alcaldes fronterizos en Ciudad Juárez, Chihuahua, en donde propusieron la creación de un fondo de resarcimiento migra torio y de repatriación en el ramo 33 de la federación. Se sostuvo, en ese entonces, que los municipios fronterizos requerían apoyos adicionales de la federación,como 
locales dar respuestas de manera conjunta e individual a problemas fronterizos que tienen un carácter federal e internacional y que provocan impactos en el desarrollo local y regional? El reto es una gestión pública fronteriza más eficaz desde una perspectiva intergubernamental, tanto en el ámbito nacional como transnacional (con Estados Unidos), en un contexto donde existen diferencias políticas, legales y económicas entre México y Estados Unidos.

\section{Problemas fronterizos y nuevos enfoques en la gestión del desarrollo regional}

El hecho de que los estados y municipios de la frontera MéxicoEstados Unidos compartan problemas fronterizos y opciones de desarrollo transfronterizo ha llevado a la necesidad de reconocer los efectos del entorno externo en las propuestas de desarrollo local y regional. En ese contexto, los gobiernos locales y estatales del norte de México cuentan con facultades legales para adoptar acuerdos interinstitucionales con sus homólogos de Estados Unidos, en los asuntos que son de su competencia Según la Ley Mexicana sobre la Celebración deTratados (Diario Oficial de la Federación, 2 enero 1992), en su artículo $1^{\circ}$ se afirma que: "[...] Los acuerdos interinstitucionales sólo podrán ser celebrados entre una dependencia u organismo descentralizado de la Administración Pública Federal, Estatal o Municipal y uno o varios órganos gubernamentales extranjeros u organismos internacionales".

Con este antecedente legal, la ley mexicana mencionada también indica que: "el ámbito material de los acuerdos interinstitucionales deberá circunscribirse exclusivamente a las atribuciones

una altemativa para atender el creciente flujo migratorio y la expulsión de migrantes, la seguridad pública, carencia de servicios, vivienda y educación. (Frontera, 13 de noviembre de 1999). 
propias de las dependencias y organismos descentralizados de los niveles mencionados que los suscriben". Según la misma ley, los tratados sólo pueden celebrarse entre el gobierno de los Esta dos Unidos Mexicanos y uno o varios sujetos de derecho internacional público. De esto se deduce que los gobiernos locales pueden únicamente promover acuerdos interinstitucionales y no tratados, que son una facultad del Estado o del gobierno federal.

La relación con los Estados Unidos se concibe como un problema y oportunidad porque la interacción se caracteriza por tensiones, conflictos fronterizos y espacios de cooperación. En ese contexto, radica la importancia de la capacidad gubernamental y de la gestión intergubernamental para promover la relación fronteriza como una oportunidad y reducir sus efectos negativos.

Algunos de los problemas fronterizos donde se puede reflejar la falta de capacidad de los gobiernos locales y deficiencias en la gestión intergubernamental son:

1. Problemas ambientales. Se considera que la región fronteriza es una de las zonas que presenta mayores problemas ambientales en el ámbito mundial. Los gobiernos federales de México y Estados Unidos han creado instituciones binacionales y, con ello, planes y proyectos binacionales para atender los problemas ambientales fronterizos. Sn embargo, a pesar de 17 años de cooperación ambiental no $s$ ha podido reducir la problemática ambiental fronteriza (Sánchez,2000) . Estos problemas $s$ atribuyen, entre otras causas, a que no existe una concepción integral y de largo plazo para atender las necesidades fronterizas. Por ejemplo, en los últimos años ha predominado un interés político, en el sentido de dar respuestas a las presiones de los grupos ambientalistas de Estados Unidos y de algunos medios de comunicación de ese país. En ese contexto, no ha sido posible articular políticas y estrategias y una gestión binacional con el fin de fomentar el desarrollo fronterizo. 
A manera de antecedentes, \& Plan Integral Ambiental Fronterizo 1992-199416 detectó, entre otros problemas, que las 20 principales ciudades fronterizas no contaban con un sis tema de tratamiento de agua; cuando existía, su capacidad era insuficiente o no funcionaba bien. Asimismo, los problemas de contaminación ambiental se han agudizado con el desarrollo del TLCAN ${ }^{17}$ y el crecimiento económico fronterizo. ${ }^{18}$

2. Las deficiencias de infraestructura. La región fronteriza no cuenta con la infraestructura de transporte necesaria para facilitar adecuadamente el comercio entre México y Estados Unidos, el cual se ha incrementado de manera importante desde el año de 1994. Se estima que cerca de cuatro millones de ca miones y 85 millones de vehículos de pasajeros han ingresado a Estados Unidos desde México en el año fiscal de 1998 (GAO, 1999). Procesar el alto volumen de tráfico comercial y el trá fico de pasajeros y, al mismo tiempo, tratar de interceptar el contrabando de drogas y la migración laboral, ha impactado en la infraestructura local de las comunidades fronterizas. El problema de infraestructura asociado a la contaminación ambiental también ha dado pie a que se carezca de infraestructura básica para el tratamiento de aguas negras en las principales ciudades fronterizas. Además, existe una insuficiencia de in-

16 Otra iniciativa más reciente es el mecanismo de planeación y coordinación bilateral denominado Border XXI, cuyo objetivo principal es lograr un medio ambiente limpio, protección a la salud pública y los recursos naturales e impulsar un desa rrollo sustentable Se basa en estrategias como éstas: participación del sector público en el desarrollo de los proyectos, descentralización de la gestión ambiental y una cooperación intergubernamental para hacer un uso eficiente de los recursos y reducir el burocratismo.

17 Algunos de esos efectos son la degradación ecológica, pérdida de agua subterránea, contaminación de mantos freáticos y generación de desechos sólidos.

18 Otros problemas en materia ambiental son el escaso financiamiento para la creación de infraestructura ambiental, el impacto ambiental transfronterizo de proyectos propuestos por los gobiernos federales de México y Estados Unidos, la protección de los recursos hidráulicos compartidos y la ausencia de programas binacionales ambientales para la atención y manejo de plaguicidas, fertilizantes y sustancias tóxicas en la producción agropecuaria. 
fraestructura en los principales cruces fronterizos a causa del crecimiento del comercio bilateral y turístico, las deficiencias en las inspecciones aduanales, lo que ha provocado demoras en los cruces fronterizos. 19 La problemática de los cruces fronterizos entre México y Estados Unidos se ha agudizado desde septiembre de 2001 a causa de la política de seguridad fronteriza del gobierno estadounidense.

Uno de los problemas principales que ha limitado el desarrollo de las propuestas binacionales en el sector de infraestructura son las diferencias en la descentralización del poder y la autoridad en Estados Unidos y en México. ${ }^{20}$ Asimismo, des taca el hecho de que propuestas binacionales reflejan las prioridades de los actores estadounidenses y, en un segundo plano, las propuestas de los actores mexicanos. Esta situación puede indicar la falta de visión del sector empresarial y de los gobiernos fronterizos del norte de México para formular una propuesta de desarrollo integral que atienda también las demandas sociales de las comunidades fronterizas. En ese contexto, se justifica la gestión intergubernamental del desarrollo regional y, además, la participación del sector empresarial y social en el diseño y elaboración de las políticas de desarrollo regional.

3. La inseguridad pública. La creciente inseguridad pública en las ciudades fronterizas del norte de México se puede atribuir, entre otros factores, a los cambios que presenta la sociedad

19 Para atender tales problemas se han creado una serie de mecanismos bilatera les, por ejemplo, el U. S. México Binational Group on Bridges and Border Crossings, la Border Coordination Initiative, el Joint Working Committee y la Border Trade Alliance, más conocida, que elaboró el informe Southwest Border Port Capital Improvements Report for Fiscal Year 2000.

20 Una propuesta binacional interesante en el ámbito local es la planteada por San Diego Dialogue y la Greater San Diego Chamber of Commerce, "Planning for Prosperity in San Diego-Baja California Region", San Diego, California, septiembre de 1993. Cabe mencionar que San Diego Dialogue ha sido una organización académi cano gubernamental que ha promovido en los últimos años la relación binacional fronteriza. 
fronteriza y que derivan - en algunos casos- de la interacción tranffronteriza. Estos cambios no han sido totalmente asimilados en la gestión pública en sus distintos ámbitos Un factor adicional son los esfuerzos de los gobiernos local, estatal y federal en materia de inseguridad pública y combate al narcotráfico, esfuerzos que han sido insuficientes para reducir o controlar la problemática.

En el aspecto social, uno de los factores que ha influido en la delincuencia fronteriza es el consumo de drogas, especialmente en estratos populares. Algunos hallazgos de la Encuesta Nacional de Adicciones de la Secretaría de Salud, efectuada entre los años de 1993 y 1998, reflejan que el consumo de drogas en México se ha incrementado en el último lustro, al pasar de 1.4 millones a 2.5 millones de personas en el periodo de 1993 a 1998 (Secretaría de Salud, 1999;Medina, 1999).0tros datos de la Encuesta indican que las ciudades deTijuana, B. C., y Ciudad Juárez,Chihuahua,sobresalen en el consumo de drogas en los ámbitos regional y nacional. 21

Entre otros factores que han influido en el aumento de la inseguridad pública en México y en las principales ciudades fronterizas del norte del pás, se encuentran: aspectos sociales (incremento demográfico, desintegración familiar y patrones de comportamiento social diverso); económicos (desempleo, empleos mal remunerados, niveles bajos de bienestar familiar e inestabilidad económica) y tendencias del desarrollo urbano (marginalidad, servicios públicos deficientes y mal distribuidos). Estos factores se ven influidos por los

21 Igualmente se afirma que en Tijuana el consumo es 2.8 veces mayor al consumo nacional y casi $\mathbf{2 . 5}$ superior al de su región. Ciudad Juárez casi duplica el promedio nacional y presenta $\mathbf{5 0}$ por ciento más de consumo que el de la zona donde se ubica. Según el Consejo Nacional deAdicciones, en 1995 Tijuana ocupó el primer lugar de las ciudades fronterizas en consumo de marihuana en términos de por lo me nos una vez en la vida, con $\mathbf{8 . 4}$ por ciento; en segundo sitio, Ciudad Juárez, con 8.3 por ciento y posteriormente Matamoros, Tamaulipas, con 0.9 por ciento. En cuanto al consumo de cocaína, Tijuana ocupaba el primer lugar con 2.7 por ciento, seguido de Ciudad Juárez con 1.8 por ciento y después Matamoros con 0.9 por ciento. 
procesos de interacción transfronteriza que existen entre Mé xico y Estados Unidos. Generalmente no han sido considerados en los análisis gubernamentales de seguridad pública fronteriza; en su lugar, se han enfatizado los aspectos de tipo penal y criminológico. Aspectos que si bien son importantes, no reflejan un enfoque transfronterizo y una perspectiva integral de la inseguridad pública que permita comprender su complejidad social, política, cultural, económica y de gestión. El contexto transfronterizo representa una variable fundamental con respecto a la inseguridad pública prevaleciente en el resto del pás. Esto conlleva a promover el diseño y desarrollo de políticas públicas específicas y en algunos casos políticas y una planeación binacional en el ámbito regional.

La magnitud de la inseguridad pública fronteriza se ejemplifica con los siguientes aspectos: según información del INEGI, en el periodo de 1990 a 1994, los delitos del fuero federal por asuntos relacionados con el narcotráfico y otros delitos, se concentraban en cerca de un 40 por ciento en los estados fronterizos del norte del pás, en donde destacaba el estado de Baja California. Un análisis de Vicente Sánchez (2000), quien empleó información de la Procuraduría General de Justicia de estado de Baja California ( PGJE), indica que entre los años 1997 y 1999 el promedio de delitos tales como homicidios, lesiones y robos registrados en dicho estado, ascendió a poco más de 30 mil, y en Tijuana a 19 mil 600. Es decir, una ocurrencia de dos tercios del total de la incidencia delictiva de tipo violento en el ámbito estatal, tiene lugar en la ciudad de Tijuana, en donde habita aproximadamente el $\mathbf{5 0}$ por ciento de la población que vive en el estado.

Los problemas de contaminación ambiental, limitaciones de infraestructura, inseguridad pública, narcotráfico y migra ción se seguirán agudizando conforme continúe el crecimiento demográfico, aumenten los cruces fronterizos y exista oferta y demanda de drogas. Esos problemas se han agravado a causa de las limitaciones en el papel de los gobier- 
nos fronterizos, en términos de su capacidad administrativa e institucional .Asimismo, ha coadyuvado una escasa y deficiente gestión intergubernamental para prever mediante la planea ción regional fronteriza sus impactos negativos.

En resumen, el papel de los gobiernos locales fronterizos en términos de su capacidad, es una tarea fundamental para promover una gestión y políticas públicas orientadas a promover el desarrollo fronterizo. Se concibe una administración binacional en la medida en que el desarrollo regional esté condicionado por los factores externos. En ese contexto, se percibe un cambio en la gestión pública fronteriza, que, como Aguilar Villanueva (1996) apunta, entre sus elementos se encuentran:

[...] destacar las transformaciones que experimentan las administraciones públicas al enfrentar nuevas circunstancias, retos, oportunidades y problemas que se derivan de la creciente interdependencia entre las naciones, a consecuencia de la dinámica de las economías abiertas, las multiformes relaciones transfronterizas y, en particular, por la aparición de problemas públicos de naturaleza transnacional que difícilmente pueden ser abordados con éxito sólo con los recursos y las acciones de una administración pública contenida dentro del perímetro de sus instituciones políticas nacionales.

Nuevos enfoques de la gestión pública

y cambios en las políticas de desarrollo regional

Las experiencias de los países de América Latina respecto a la política de desarrollo local y de fomento productivo, de manera generalizada, se reservaron como áreas de intervención exclusiva para $\mathrm{el}$ Estado. Además, el proteccionismo comercial, el sobredimensiona miento de los aparatos estatales y los problemas estructurales - escasa productividad, escasa capacitación, problemas de financiamiento del sector empresarial - ,impidieron un mayor pa pel para promover la competencia. 
Las reformas económicas de los países latinoamericanos se han caracterizado por la apertura de las economías hacia el exterior, de la desregulación de los mercados y de la amplia privatización de empresas estatales, las cuales plantearon nuevos desafíos al sector empresarial, en el sentido de cómo enfrentar un mayor grado de competencia en los mercados mundiales y nacionales (Colmenares, 2001). Desde esta perspectiva, a partir de la segunda mitad de la década de los noventa, se viene planteando la necesidad de llevar a cabo una segunda fase de un ajuste estructural, en donde se considere la introducción de ciertas reformas de Estado. De manera especial, se plantea la creación de instituciones económicas en los gobiernos locales. Su finalidad es reforzar el cambio estructural que privilegie la competitividad y el bienestar social.

En este esquema, la gestión y las políticas públicas se orientan a promover una calidad de vida a través del fomento productivo. Este enfoque implica un cambio en la estrategia de desarrollo seguida hasta hoy. Se trata de una política que se caracteriza por la dualidad del fomento productivo: por un lado, los programas sectoriales de fomento a las exportaciones se han orientado hacia las empresas grandes y modernas y, por otro, los apoyos a las micro y pequeñas empresas constituyen la parte fundamental de las políticas de combate a la pobreza (Colmenares,2001). Según el propio Colmenares, en el presente se pone de manifiesto que ambas tendencias han sido divergentes, entre otras razones, por la ausencia de un enfoque de desarrollo local en las estrategias nacionales de desarrollo económico. Por ello, entre las estrategias fundamentales que se pretenden reforzar se encuentran las transferencias de funciones hacia los gobiernos locales. En ello, la descentralización y modernización de la gestión local tendrían el rol principal en cuanto a generar nuevas condiciones y actores para el surgimiento de iniciativas de desarrollo local, en virtud de las importantes funciones sociales y económicas transferidas a los estados y municipios.

En la estructuración de dicha política, se proponen una serie de estrategias de gestión y políticas locales, por ejemplo: impulsar 
reformas administrativas, reforzar las competencias de planeación; incrementar los flujos de información base para la planeación; fomentar la cooperación intermunicipal en la ejecución de proyectos de infraestructura; incrementar la coordinación regional para la infraestructura y política social y, finalmente, la introducción de nuevas formas de gestión cooperativa regional y local, como vía para compensar déficits, obtener recursos y mejorar la oferta de servicios.

Actualmente, y siguiendo un informe de la OCDE sobre perspectivas territoriales, se afirma que las políticas territoriales son cada vez más necesarias y no se limitan a ser una mezcla de pla neación espacial y políticas regionales. Esas políticas abarcan el conjunto de las acciones de los gobiernos para promover el desa rrollo de todas las entidades federativas, municipios y ciudades que integran un país; buscan disminuir las desigualdades entre ellas, en particular nivelando las oportunidades de desarrollo (De María y Campos, 2001).

En resumen, las políticas de desarrollo local y regional se enfrentan a los siguientes retos: 1) valorar el potencial de los gobiernos locales y estatales de los estados fronterizos. Un aspecto crucial para las políticas de promoción económica local es la adaptación a las realidades geográficas y territoriales. 2) la nueva economía es global, pero importantes funciones económicas continúan siendo regionales y locales. 3) la promoción del desarrollo local y regional es un esfuerzo sistemático de adaptación y de cambio. Las localidades que no adopten este comportamiento quedarán fuera del dinamismo económico y del desarrollo. Considerado de esta manera, el desarrollo local y regional exige un nuevo rol para los directivos locales. En primer lugar, ser estrategas. Para ello se deben analizar las fuerzas que afectan la economía local, tener una visión y capacidad de influir sobre el futuro, trasladar esta visión a todos los actores y, fundamentalmente, gestionar las políticas con una visión integral e interguberna mental.Asimismo, se requiere construir el liderazgo y el consenso necesarios para impulsar la estrategia. 
En suma,la visión del futuro, el consenso y las capacidades de gestión y de negociación para construir alianzas, resultan claves para actuar en torno a los objetivos económicos y de desarrollo comunes.

\section{Consideraciones finales}

La premisa planteada en este artículo es que un papel eficaz de los gobiernos de los estados fronterizos, respaldada en la capacidad gubernamental y en la gestión intergubernamental, es un requisito para fortalecer las políticas de desarrollo regional en el norte de México, particularmente cuando el desarrollo regional se asocia a aspectos de tipo social, económico, político y cultural.

Se ha fundamentado teóricamente la premisa anterior, destacando para ello la importancia, los contextos y algunos elementos que condicionan el papel de los gobiernos fronterizos para promover el desarrollo regional en la frontera México-Estados Unidos. Esto conlleva la gestión tanto de asuntos estrictamente fronterizos (en un ámbito nacional) como asuntos transfronterizos (en estadounidenses).

La reformulación de políticas públicas es un requisito para superar las deficiencias en sus procesos de gestión, particularmente cuando está en juego la legitimidad de los gobiernos locales. En ese marco, el empleo de nuevos enfoques de gestión pública representa una de las alternativas para rediseñar políticas ineficaces en un contexto de recursos escasos, inercias burocráticas e influencia de factores políticos.

La falta de tradición democrática y de división de poderes, es un obstáculo para fomentar las relaciones entre los actores y los ámbitos de gobierno en donde predominen la negociación, la cooperación y el conflicto. El reto es reducir y en su momento evitar tales limitaciones que han obstaculizado el desarrollo fronterizo en el norte del país. No será posible reducir esas limitaciones en el corto plazo, porque sus causas tienen un carácter estructu- 
ral, que en parte obedece a la propia conformación del Estado mexicano. Por consiguiente, el reto sigue siendo avanzar hacia una gestión intergubernamental en los asuntos fronterizos en un marco de descentralización y centralización. Ello implica reconocer las competencias de cada ámbito gubernamental en materia de la administración del desarrollo regional fronterizo.

El hecho de que en los últimos años se hayan agudizado las tensiones fronterizas en materia de migración laboral, narcotrá fico, inseguridad pública, cruces fronterizos, contaminación ambiental, demandas de infraestructura e impactos locales de políticas económicas federales, entre otros asuntos, refleja la dificultad de reducir sus impactos. Esos problemas cuestionan la ausencia de una planeación del desarrollo regional y el diseño de políticas transfronterizas. En ese contexto, se requiere voluntad política, conocimiento y capacidad gubernamental en los actores nacionales para establecer las condiciones institucionales en México y de rediseñar los procesos y políticas en materia de desarrollo regional.

La reformulación del papel de los gobiernos fronterizos con Estados Unidos es una respuesta a los procesos de globalización, un nuevo papel del Estado, el carácter transnacional de los problemas fronterizos y, principalmente, de que las políticas del gobierno federal con respecto a la frontera norte no han logrado reducir los problemas fronterizos. De ahí que otro de los retos de los gobiernos y la gestión pública sea el de tratar de rediseñar los procesos de toma de decisiones con una mayor consideración a los aspectos sociales. $Y$ en general del resto de los factores institucionales y económicos que condicionan el desarrollo regional en la frontera México-Estados Unidos.

Resta reflexionar, a manera de conclusión, si es posible que el avance en la transición democrática con el gobierno del presidenteVicente fox cambie la situación imperante en materia de gestión del desarrollo regional en el norte de México. Por un lado, se ha llegado a la conclusión general de que los gobiernos panistas en los estados fronterizos del norte de México se han preocupa do por fomentar ciertos niveles de eficiencia en la administración 
pública local y regional (Ward,1998; Guillén y Ordóñez, 1995, y Mizrahi, 1996). Sin embargo, ha resultado difícil concebir un diseño y una planeación integral del desarrollo regional.22 Por ejemplo, en algunos casos, los gobiernos de formación panista han reproducido en los ámbitos local y regional, tendencias de centralización, coordinación y cooperación intergubernamental inadecuada, corrupción, escasa transparencia en los procesos de toma de decisiones, una escasa o nula institucionalización de procesos administrativos y, particularmente, la dificultad de establecer consensos en el diseño e implantación de políticas públicas, al margen de las diferencias ideológicas con el resto de los actores políticos y la sociedad civil. Una explicación preliminar de estas tendencias obedece a la existencia de una cultura política y de gestión tradicional, aunado a las limitaciones en la capacidad gubernamental.

Para resumir, la alternancia democrática no ha significado un cambio sustancial en la manera de concebir y planear el desarrollo fronterizo en el norte de México, si se compara con administraciones públicas de los gobiernos prí́stas en años anteriores Particularmente, a través de adoptar una capacidad gubernamental con una visión estratégica y el de concebir un equilibrio o un consenso entre las prioridades del crecimiento económico con una visión empresarial y las demandas sociales fronterizas ${ }^{23} \mathrm{Un}$ riesgo de conceder mayor importancia a tal visión - empresarial-, puede dar pie a la corrupción gubernamental a través de financiamientos públicos y concesiones. Sobre todo cuando no

\footnotetext{
22 Una propuesta institucional interesante es la Comisión de Asuntos de la Frontera Norte, coordinada por Ernesto Ruffo Appel. Sin embargo, limitaciones de tipo legal, institucional y político han determinado hasta la fecha (abril de 2002), un escaso impacto para coordinar el desarrollo fronterizo.

23 No ha sido el objetivo de este artículo valorar el papel de los gobiernos de tendencia panista en el conjunto de las políticas públicas en el ámbito local o estal en los estados de la frontera norte mexicana; el objetivo general ha sido el de desta car algunos problemas o contextos que han condicionado el papel de esos gobiernos para promover la cooperación y planeación del desarrollo regional desde una pers pectiva fronteriza (nacional) y transfonteriza (Estados Unidos).
} 
existe transparencia en los procesos de toma de decisiones y al no existir una clara separación entre funciones públicas y los intereses privados.

Recibido en septiembre de 2001 Revisado en abril de 2002

\section{Bibliografía}

Agranoff, Robert, et al. (1994), "Building Development Capacity in Nonmetropolitan Communities", Public Administration Review, vol. 54, no. 5, pp. 426-433.

(1997), "Las relaciones y la gestión intergubernamentales", en Rafael Banón y Ernesto Carrillo (comps), La nueva ad ministración pública, Madrid, Alianza U niversidad, pp. 125-170.

y Michael McGuire (1998), "Multi-Network Management Collaboration and the Hollow State in Local Economy Policy", Journal of Public Administration Research andTheory, vol. 8, no. 3, enero, pp. 67-91.

AguilarVillanueva, Luis F. (1992), El estudio de las políticas públicas, Miguel Ángel Porrúa (Antología de Políticas Públicas),pp. 39-54.

(1996a), "El federalismo mexicano: funcionamiento y tareas pendientes", en Alicia Hernández (coord.), ¿Hadia un nue vo federalismo?, FCE-COLMEX, pp. 109-152.

(1996b), Prólogo en José María Ramos, Desarrollo regional y relación transfronteriza. El caso de M éxico-California, México, Instituto Nacional de Administración Pública.

(2002), "La nueva gestión pública: origen y desarroIlo", conferencia magistral, Tijuana, B. C., El Colegio de la Frontera Norte, 24 de enero. 
Barzelay, Michael (1992), Breaking Through Bureaucracy. A N ew Vision for Managing Government, The Regents of the University of California, University of California Press

Brugué, Quim y Ricard Gomá (1998a), “Gobierno local: de la na cionalización al localismo y de la gerencialización a la repolitización", en Quim Brugué y Ricard Gomá (coords.), Gobiernos locales y políticas públicas, bienetar social, promoción económica y territorio, España,Ariel, pp. 16-23.

(1998b), "Las políticas públicas locales: agendas complejas, roles estratégicos y estilo relacional", en Quim Brugué y Ricard Gomá (coords.), Gobiernos locales y políticas públicas, bienes tar social, promoción económica y territorio, España,Ariel, pp. 25-35.

(1998c), "La dimensión local de la promoción económica: el marco conceptual", en Quim Brugué y Ricard Gomá (coords.), Gobiernos locales y políticas públicas, bienestar social, promoción económica y territorio, España,Ariel, pp. 118-132.

Bustamante, Jorge A. (1995), "Administración municipal y relación bilateral", en Tonatiuh Guillén y Gerardo Ordóñez (coords.), El munia pio y el desarrollo social dela frontera norte, México, COLEF-Fundación Friedrich Ebert, pp. 297-308.

Cabrero, Enrique (1998), "Estudio introductorio”, en Barry Bozeman (coord.), La gestión pública. Su situación actual, Colegio Nacional de Ciencias Políticas y Administración Pública, Universidad Autónoma deTlaxcala y FCE, pp 19-36.

Clemente, Adriana (2000), "El papel de las ONG's en el desarrollo local. Indicadores para la gestión asociada y el trabajo en alianza", Síntesis, no. 33-34, enero-diciembre.

Colmenares, David (2001), "Esfuerzos para el desarrollo regional", El Financiero, 23 noviembre. 
Crozier, Michael (1987), Estado modesto, Estado moderno, México, FCE.

Cuadrado Roura, Juan R. (1995), "Planteamientos y teorías dominantes sobre $\mathrm{e}$ crecimiento regional en Europa en las cuatro últimas décadas", Revista Latinoamericana de Estudios U rbano-Regionales (EURE), Santiago de Chile, vol. XXI, no. 63, pp. 5-32.

(1988), "Políticas regionales: hacia un nuevo enfoque", Papeles de Economía Española, no. 35, Madrid.

De María y Campos, Mauricio (2001), “Las políticas territoriales, complemento indispensable de las políticas macroeconómiCas: OCDE", El Financiero, 21 de agosto.

De Mattos, Carlos A. (1997), "Evolución de las teorías del crecimiento económico y crisis de la enseñanza urbano-regional", ponencia del 1997 Annual M eeting de la Association of Collegiate Schools of Planning, Fort Lauderdale, Florida, 6-9 de noviembre, p. 13.

Dror, Yehezkel (1995), "Las capacidades de gobernar y la integra ción Europea", Gestión y análisis de políticas públicas, no. 4,septiembre-diciembre, Madrid.

(1997), "Fortalecimiento de la capacidad de los gobiernos en materia de formulación de políticas", Gestión y aná lisis de políticas públicas, septiembre-abril, Madrid.

General Accounting Office (1999), U.S.-M exico Border. Issues and Challenges Confronting the United States and Mexico, Report to Congressional Requesters, Washington, D. C., julio, p. 51.

Gomá, Ricardo y Joan Subirats (1998), Políticas públicas en España. Contenidos, redes de actores y niveles de gobierno, Barcelona,Ariel. 
Guillén, Tonatiuh y Gerardo Ordóñez (coords.) (1995), El muni d pio y el desarrollo social de la frontera norte, México, colef-Fundación Friedrich Ebert

Hooghe, L.(ed.) (1996), Cohesion Policy and European Integration:Building a M ultilevd Governance, Oxford, University Press.

Keating, Michael (1993), Regionalismo, autonomía y regímenes internacio nales, Barcelona, Institut de Ciences Politiques i Sociales.

Lindblom, Charles (1991), El proceso de elaboración de políticas públicas, Ministerio de Administraciones Públicas, Madrid.

Lynn, Lawrence E. (1998), "The New Public Management How to Transform a Theme into Legacy", Public Administration Review, vol. 58, no. 3.

Mead, Thimoty (1981), "Identifying Management Capacity Among Local Governments", U rban Affairs Papers, no. 3,pp. 1-12.

Medina Mora, María Elena (1999), “Los jóvenes y el uso de drogas en México", ponencia presentada en la Segunda Conferencia Binacional M éxico-Estados Unidos sobre Reducción de la Demanda de Drogas, Tijuana, B. C., junio.

Mizrahi,Yemile (1996), “'Administrar o gobernar? El reto del gobierno panista en Chihuahua", Frontera N orte, vol. 8, no. 16, julio-diciembre, Tijuana, B. C., colef.

Olías de Lima, Blanca (2001), "Evolución de la gestión pública: La nueva gestión pública", en Olías de Lima, B., La nueva getión pública, Madrid, Prentice Hall, pp. 1-34.

Ramos García, José María (1995), California Policies Towards M exico: Proposal and Binational Impacts, Research Report, COLEF-CONACYT, octubre. 
(1996), Desarrollo regional y redación transfronteriza. El caso de Mé xico-California, México, Instituto Nacional de Administración Pública, pp. 157.

(2002), Comentarios a la conferencia magistral de Luis F. AguilarVillanueva, "La nueva gestión pública:origen y desa rrollo", 24 de enero, Tijuana, B. C.

Rico Ferrat, Carlos (1989), “Modelos implícitos y explícitos en la evaluación de la capacidad de negociación intergubernamental", Foro Internacional, vol. xxIx, no. 4, abril-junio, El Colegio de México, pp. 693-712.

Richardson, Harry W. (1973), Regi onal Growth Theory, The MacMillan Press, London.

(1975), Política y planeación del desarrollo regional en España, Ma drid, Alianza Universidad.

Saint-Germain, Michelle (1995), "Similarities and Differences in Perceptions of Public Service Among Public Administrators on the U.S.-Mexico Border", Public Administration Review, vol. 55, no. 6, noviembre-diciembre, pp. 507-516.

Sánchez, Roberto (2000), Binational Cooperation and the Environment at the U.S.- M exico Border. A M exican Perspective, Santa Cruz,U niversity of California.

Sánchez, Vicente (2000), "Panorama general de la inseguridad pública en Tijuana", en José María Ramos, Vicente Sánchez Munguía, Noé Fuentes Flores y Rafael Vela González, Diagnósti co de riesgos para la seguridad pública en Tijuana, B. C., informe final de investigación, coLEF, octubre

Secretaría de Salud (1999), El consumo de drogas en México: diagnóstico, tendendias y acdi ones, México. 
Simon, H .A. (1957), Administrative Behaviour, Londres, McMillan.

Sosa, José ( 1999), “Modernizar la administración fronteriza: ¿una tarea pendiente?", Anuario M éxico-Estados Unidos-Canadá, 1998, EI Colegio de México, pp. 119-156.

Vogelsang-Coombs, Vera y Mellisa Miller (1999), "Developing the Governance Capacity of Local Elected Officials", Public Ad ministration Review, vol. 59, no. 3, mayo-junio, pp. 119-217.

Ward, Peter (1998), “Del clientelismo a la tecnocracia: cambios recientes en la gestión municipal en México", Política y Gobier no, vol. v, no. 1, CIDE, pp. 95-133.

Wright, Deil (1997), Para entender las relaciones intergubernamentales, Nuevas lecturas de política y gobierno, México, Colegio $\mathrm{Na}$ cional de Ciencias Políticas y Administración Pública, Universidad Autónoma de Colima y FCE. 